\title{
Towards a Framework for Teaching Artificial Intelligence to a Higher Education Audience
}

BECKY ALLEN, ANDREW STEPHEN MCGOUGH, and MARIE DEVLIN, Newcastle University, UK

Artificial Intelligence and its sub-disciplines are becoming increasingly relevant in numerous areas of academia as well as industry and can now be considered a core area of Computer Science [84]. The Higher Education sector are offering more courses in Machine Learning and Artificial Intelligence than ever before. However, there is a lack of research pertaining to best practices for teaching in this complex domain which heavily relies on both computing and mathematical knowledge. We conducted a literature review and qualitative study with students and Higher Education lecturers from a range of educational institutions, with an aim to determine what might constitute best practices in this area in Higher Education. We hypothesised that confidence, mathematics anxiety and differences in student educational background were key factors here. We then investigated the issues surrounding these and whether they inhibit the acquisition of knowledge and skills pertaining to the theoretical basis of artificial intelligence and machine learning. This article shares the insights from both students and lecturers with experience in the field of AI and machine learning education, with the aim to inform prospective pedagogies and studies within this domain and move towards a framework for best practice in teaching and learning of these topics.

CCS Concepts: $\bullet$ Social and professional topics $\rightarrow$ Computing education; $\bullet$ Computing methodologies $\rightarrow$ Artificial intelligence. Additional Key Words and Phrases: Artificial Intelligence, pedagogy, self-efficacy.

ACM Reference Format:

Becky Allen, Andrew Stephen McGough, and Marie Devlin. 2021. Towards a Framework for Teaching Artificial Intelligence to a Higher Education Audience. ACM Trans. Comput. Educ. 1, 1, Article 1 (January 2021), 28 pages. https://doi.org/10.1145/3485062

\section{INTRODUCTION}

The field of Artificial Intelligence (AI) endeavors to not only try to understand what constitutes intelligence, but to create and build intelligent systems [77]. Within the field of AI there are a number of specific application areas such as robotics and computer vision as well as domains such as machine learning (as shown in Figure 1). Machine learning is "a branch of artificial intelligence that allows computer systems to learn directly from examples, data, and experience" [93]. This capability enables computers to perform tasks by learning from data instead of using pre-programmed rules. Within machine learning, is the field of deep learning which has contributed to the resurgence in the use of AI due to its advances and phenomenal successes in fields such as computer vision, boosting the application of this technology within industry and increasing the popularity of the subject amongst students. For the sake of clarity, AI will be used to denote courses encompassing machine learning and deep learning throughout this paper, without loss of generality.

Individuals with knowledge and experience of AI are highly sought after within industry and the current skills shortage within this sector is becoming an increasing problem for recruiters, with the demand for specialists rising

Authors' address: Becky Allen, B.Allen2@newcastle.ac.uk; Andrew Stephen McGough, Stephen.McGough@newcastle.ac.uk; Marie Devlin, marie.devlin@ newcastle.ac.uk, Newcastle University, Science Square, Newcastle Upon Tyne, UK, NE4 5TG.

Permission to make digital or hard copies of all or part of this work for personal or classroom use is granted without fee provided that copies are not made or distributed for profit or commercial advantage and that copies bear this notice and the full citation on the first page. Copyrights for components of this work owned by others than ACM must be honored. Abstracting with credit is permitted. To copy otherwise, or republish, to post on servers or to redistribute to lists, requires prior specific permission and/or a fee. Request permissions from permissions@acm.org.

(c) 2021 Association for Computing Machinery.

Manuscript submitted to ACM

Manuscript submitted to ACM 


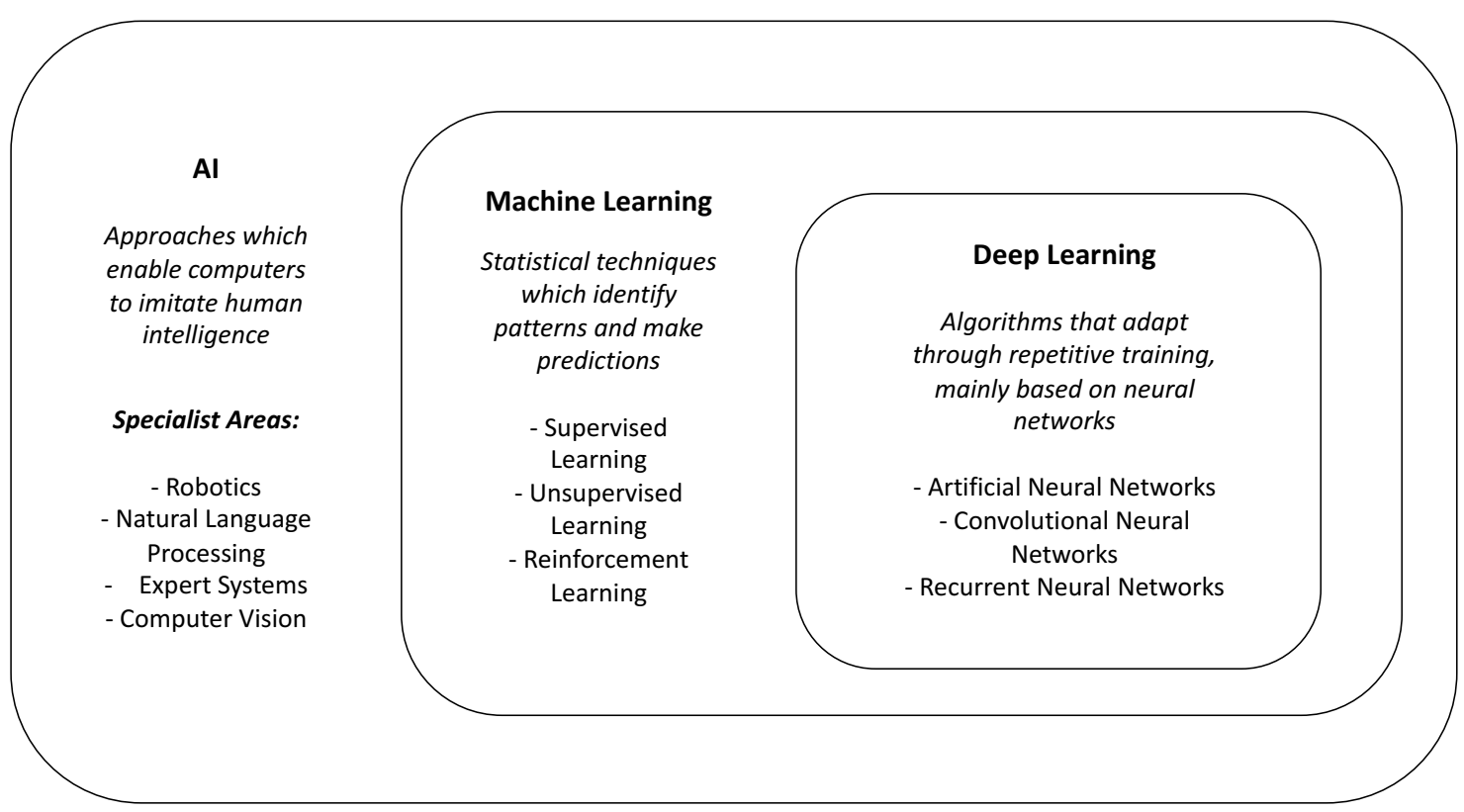

Fig. 1. Overview of Al, Machine Learning and Deep Learning (based on [15][48])

as the UK digital economy grows [26], the same trend is assumed for the rest of the world. Interest in this subject at Higher Education (HE) level is also increasing, resulting in many educational institutions offering some form of AI course, for example, in the UK in 2017 there were twenty-six universities offering undergraduate courses in AI and more than thirty graduate programmes running across twenty universities [42]. More recent findings in 2021, suggest that there is a demand to expand places by a "five to tenfold increase" [94]. However, whilst the uptake of AI courses has been increasing steadily, the number of students taking such courses is still not enough to fill the UK skills gap and "estimates both of potential and predicted growth in the use of AI in the UK would require significant increases in numbers at both levels [Undergraduate and Postgraduate] to be realised in practice" [35]. There is a similar trajectory in the US and European Union [85], 93\% of US and UK organisations state that they consider AI to be a priority to their business, however $51 \%$ acknowledge that they do not have the right amount of staff to implement their AI strategies [8].

Two issues that may impact on attracting and retaining students within this topic are 1. the best practices in pedagogy to teach the specialist skills required are still relatively unexplored, 2. AI is an advanced subject that combines aspects from both mathematics and computer science where students may lack confidence in their ability to do well in such courses, especially if they suffer from mathematics anxiety or have a general lack of confidence in their technical skills. Mathematics anxiety "involves feelings of tension and anxiety that interfere with the manipulation of numbers and the solving of mathematical problems" [73]. The level of mathematics and computer science required to understand and execute machine learning is often not taught within a single course. The level of technical skills required by the student is determined by the type of AI course they are undertaking. There are two main strands of AI education, how to apply these techniques and how to create and innovate new AI methodologies. The prerequisites will differ based upon the type of AI course with the latter requiring greater in-depth mathematical knowledge. 


\subsection{Case Study Overview}

In our study, qualitative research and existing studies have been used to determine the opinion in the scholarly community regarding this technology. Determining any misconceptions prospective AI students may have will help to identify the already embedded mental model and inform on the need to clarify any misinterpretations. Gaining a greater understanding of the opinions of AI may also lead the development of strategies to encourage more people to become skilled - thus accommodating the rising demand. The case study will aim to provide findings relating to the two issues identified in the previous section in relation to attracting and retaining students.

Recent surveys undertaken by Cameron [12] and Ipsos MORI [45] indicate that individuals who could be deemed "digital natives", a term coined by Prensky [68] to indicate individuals who grew up with computer and internet access, are more familiar with the term machine learning. These studies also indicated that the participants were not particularly interested in how machine learning worked, this was "in part due to the complexity of the technology being something they assumed they would not be able to understand" [12]. The opinion that machine learning is too complex to understand may be an issue with the recruitment of appropriate candidates to courses. It may also lead to confidence issues amongst students who are undertaking an AI module but who are not specialists in computer science and are studying another domain.

Investigating the prior mathematics attainment level of students on AI courses, alongside the current UK HE offerings in mathematics could determine whether there are any topics or skill gaps which could lead to difficulties for students taking these courses. Data science courses were also reviewed as this field is "still in its formative period" [98] and there is yet to be a definitive definition of the tools and methods within this discipline, however, some data scientists are competent in machine learning [28].

We set out to understand some of the barriers students may face when trying to learn AI. We particularly focused on confidence level and self-efficacy and how this might impact their willingness or ability to learn. Steven [88], advises that "there will rarely be only one barrier facing a particular group," instead students are perhaps encountering a number of barriers which may amalgamate. Prior research pertaining to barriers students may face often use a deficit model, where the underrepresented group are charged with overcoming these issues, "rather than assessing the impact of institutional infrastructure, entry requirements, course structure and student experience" [88]. We also investigated metacognition which is our "ability to articulate and regulate the mental processes that we use to construct our knowledge, understanding and skills" [58]. Metacognition, self-regulation and self-efficacy are concepts which have been identified to "help students to organize their study activity independently and effectively" [14]. We decided to look at these factors as well as the personal experiences and capabilities of the students themselves. To do this we used $\mathrm{AI} /$ machine learning modules at three different universities as our case studies. In the case studies we used student questionnaires, observation, and interviews with the lecturers within two undergraduate modules and one postgraduate module, however there were limitations to data collection due to student participation being optional.

We believe that the identification of the threshold concepts within this domain will enable better teacher understanding of the specific topics that can cause students difficulty and help guide future learning design and best practice. Threshold concepts often cause difficulty for students but can also lead to greater understanding of key ideas within the field of AI if taught effectively. Walker [96] advises that threshold concepts are usually the parts of the course where students 'get stuck' and that they can be regarded as a "particular state of expert knowledge." Students who have not yet fully understood a threshold concept attempt to learn new ideas in a more disjointed manner as they cannot yet integrate 
this new concept into their way of thinking. Students with sophisticated metacognition will be equipped to navigate through threshold concepts as metacognitive processes are "associated with enhanced cognitive performance" [58].

Once the threshold concept has been comprehended, the student can then integrate different aspects of the overall subject into their analysis of problems [51]. Preparing for threshold concepts within lessons should ensure that lecturers can implement strategies to aid students when they encounter these concepts, demonstrating that they can tolerate learner confusion [21] and help them formulate differing approaches to better student understanding. Students' can often have a muddied path towards learning which, unless communicated to the lecturer, can often lead to miscommunication regarding student progress [57].

This paper contributes to the limited research relating to teaching AI and outlines an initial framework of the best practices for teaching in this domain through identification of barriers students encounter within AI courses. To aid the design of our study we reviewed previous work in the area. Section 2 provides a literature review relating to education and the potential barriers students and lecturers may face. Section 3 details the research methods used in this study to determine the current provision relating to AI education and experiences of students and lecturers. Section 4 describes the current pedagogical offerings within this domain and the results from student and lecturer interaction. Sections 5, 6 and 7 discuss the overall findings of the research, the limitations of this study and future work

\section{BACKGROUND}

A literature review was carried out to determine current practice and existing research within the field of AI and education. Keywords were identified to construct a search strategy pertaining to AI, these included 'artificial intelligence' and disciplines within this field including 'machine learning', 'deep learning' and 'data science'. The field of data science was included as it can cover a multitude of topics from collecting, cleaning and analysing data and often application of a range of machine learning techniques [78].

The term Artificial Intelligence was conceived of in 1956 at the birthplace of the field, Dartmouth College, by John McCarthy. Alongside colleagues McCarthy hosted a two-month project relating to the study of AI. Following a number of successes, AI became a booming industry during the 1980's, however companies failed to deliver on their excessive promises leading to what was termed the "AI Winter" [77]. However, recent changes in technology and the arrival of Big Data [59] has led to a resurgence in AI popularity and it is now viewed as a solution to a large range of problems, consequently becoming embedded within the infrastructure of a range of industries.

Due to the AI resurgence, inclusion of AI within the HE computer science curricula has been expanding and the popularity of these courses fast increasing with a number of universities now offering AI specialisms. However, there is a need for more AI based courses, including MOOCs (Massive Open Online Courses) and continuing professional development courses to increase the number of people trained with these specialist skills [35]. To take advantage of AI technology, and for this domain to be widely accepted and disseminated, a significant proportion of the population need to be trained in this area [53]. Relatively little research has been undertaken regarding the best practice for teaching AI, with an increasing demand for graduates with these skills it is important to analyse how these topics are currently being taught and gain comprehension of the staff and student experience.

A review of the recent literature produced very little in terms of identifying educational best practice relating to AI, we therefore widened our search to include related topics within computer science, particularly data science courses. We felt this would give a clearer understanding of the difficulties faced by students of similar topics, which may also arise on an AI course. We also identified current practice within computing education leading us to the hypothesis that mathematics anxiety and low confidence may be a deterrent to studying AI and may also cause difficulties for students Manuscript submitted to ACM 
on these courses. It has been shown that self-efficacy and self-regulation are intrinsically linked to mathematics anxiety [47], therefore strategies to improve student self-efficacy, in turn leading to further self-regulation may be an appropriate mitigation strategy. Academic self-regulation involves awareness and orientation of both cognitive and metacognitive processes alongside execution of appropriate learning strategies to achieve specific learning outcomes [47][65]. Even if the hypothesis of mathematics anxiety does not hold true, improving student self-efficacy and self-regulation will better equip students in their learning. Identifying the potential threshold concepts is an important step towards a framework of best practice within $\mathrm{AI}$ as it will enable course leaders to focus on topics which are integral to understand the field [21] and plan strategies to ease the students through the transitional liminal space.

\subsection{Overcoming Mathematics Anxiety and Improving Student Confidence}

2.1.1 What is Mathematics Anxiety? Mathematics anxiety can be related to a number of negative consequences including avoidance of subjects which contain elements of mathematics [2] and can affect the success of the most intelligent and determined students [44]. Mathematics anxiety is a prevalent issue in the UK, with around $20 \%$ of people experiencing difficulties in this area, the percentage rises to up to $35 \%$ among the younger population [6]. The variability of course cohorts in respect to societal and educational environmental background has also been shown to be linked with educational motivation constructs including self-efficacy and anxiety relating to mathematics [54]. For example, mathematics self-efficacy and anxiety can be related to the "notion of culturally diverse sources of self-formulation" [54]. In turn, there is a correlation between anxiety and self-efficacy and the influence on academic performance, particularly in mathematics [46]. One of the possible factors of this is that students who possess a high level of self-efficacy usually show greater persistence and more sustained effort when faced with educational challenges [67]. A study by Hunt et al. [43] into mathematics anxiety levels within the British undergraduate student population indicated that "maths[sic] anxiety was significantly greater in women than men." An unanticipated finding from the study by Hunt et al. was the prevalence of mathematics anxiety among students studying within the science faculty, this was higher than anticipated. An analysis of current AI education provision will determine the expectation of mathematics skill level for students within this domain as well as identify specific mathematical content taught within these modules. Determining demographics, mathematics attainment level and confidence in mathematics skills with case study participants will identify a profile relating to mathematics for the cohorts studying on these specific AI modules.

2.1.2 Strategies to Alleviate Mathematics Anxiety. A number of strategies to alleviate mathematics anxiety have been trialed. These interventions include strategies aimed at affecting the whole class through curriculum changes and experimentation with differing psychological treatments [40][72][79]. Psychological interventions in the literature varied between behavioural strategies aimed at alleviating negative emotions towards mathematics and cognitive models which attempted to relieve concerns expressed by the student [40]. Psychological treatments which proved the most effective in tackling this anxiety included systematic desensitization, increased mathematics exposure, anxiety management and relaxation training [40][72]. One of the main shortcomings of these methods is the requirement of specially trained staff who may not be available to carry this out. Lowering student levels of mathematics anxiety can show improvement and increases to mathematics assessment scores [40]. Ramirez [72] suggests that poor self-regulatory processes in students can lead to lower perception of personal competence. Implementing strategies for improving students' self-efficacy may ease mathematics anxiety and boost student confidence in their mathematics ability, this is relevant to the issues outlined in the Introduction which may impact on attracting and retaining students. Classroom interventions and curriculum strategies aimed at reducing mathematics anxiety include the use of games and interactive 
platforms, providing specialist equipment and using different techniques for delivery of course material (e.g. group work or tutorials) [40][72]. Refreshing the format of lessons is an easy objective, likewise the use of interactive platforms and peer interaction may provide an attainable way to reduce mathematics anxiety within AI courses. We investigated the prevalence of this approach within the case study. Differing pedagogical approaches relating to changing student mind-set have also been trialed such as changing the perception of failure as an important positive learning process and the viewing of mathematical problems as a challenge rather than a threat [72]. To identify cognitive changes in students, lecturers need to be familiar with a range of learning interventions, such as; determining a student's prior understanding when they are approaching a task, having a comprehensive understanding of the material so that they can provide meaningful and challenging experiences to ensure progressive development and identifying when a student has completed the learning outcomes [37].

Approaches such as retesting and self-paced learning have been shown to reduce a student's mathematics anxiety [44]. Retesting is a tool used to motivate students to relearn to a mastery level, skills and concepts which they had not initially fully comprehended [50]. Self-paced learning can alleviate mathematics anxiety through alignment with learning goal orientation instead of performance goal orientation [44]. These approaches will be considered for implementation if a prevalence of mathematics anxiety is found in the case study. The use of distance learning incorporating technology has also been shown to be a successful strategy due to the "anonymity of an online course" [44]. Distance learning can be thought of as the provision of education at a geographically distant location, it often encompasses different learning mediums to provide a range of educational circumstances [62]. Taylor and Mohr [89] created an online distance learning mathematics course which used student centered strategies such as informal language, relevant contextual materials and reflective practice techniques with the dual aim of improving students' mathematics knowledge as well as alleviating mathematics anxiety. $90 \%$ of the students reported that the course had improved their confidence relating to mathematics. This research also suggested that distance learning may be more encouraging for students who are reluctant to discuss their past mathematics issues within a classroom environment.

2.1.3 Key Points. The presence of mathematics anxiety can impact upon the attainment of students and is interlinked with self-efficacy, a construct which also influences performance. Therefore, it is important within the case study to determine the pervasiveness of mathematics anxiety within current AI cohorts. There are a number of approaches to alleviating mathematics anxiety such as psychological interventions, pedagogical approaches and self-paced and distanced learning. Distance learning as a method for alleviating mathematics anxiety seems the most relevant approach in relation to AI at HE level as this approach can encompass a number of the other strategies such as retesting, self-paced learning and interactive games. The use of this method may play a key role in the framework for teaching AI as a learning resource to assist lecturers in leveling up student's mathematics knowledge. Tackling mathematics anxiety is pivotal as it can impact upon other areas of study which contain threshold concepts with some form of numerical content [70]. If the threshold concepts within this domain are identified and have a mathematics focus, then strategies can be implemented to assist the learner in mastering the threshold concept.

\subsection{Threshold Concepts}

Threshold concepts can be identified through a set of characteristics which define them as core concepts which potentially impede learning. These characteristics are defined as transformative, irreversible, integrative, bounded and potentially troublesome [61]. The main property of a threshold concept is its transformative nature, ensuring that a previously inaccessible way of thinking about a specific topic occurs. The irreversible tendency of threshold concepts Manuscript submitted to ACM 
ensures that once a topic is understood it cannot be 'unlearned.' Comprehension of a topic considered a threshold concept can reveal relationships between subject areas which were previously thought of as disparate, however threshold concepts can also be bounded, meaning that each concept does not generally explain the complete discipline. The basis of a threshold concept is that it is inherently troublesome to learn, sometimes the concept may be counter-intuitive to beliefs a student may already have regarding a specific subject [4].

The key threshold concepts relating to AI have not yet been clearly determined. Identifying the troublesome aspects of this field will enable greater understanding of the difficulties both students and lecturers may encounter within education in this domain. Awareness of these threshold concepts may also signpost possible strategies for lecturers to implement to aid students in overcoming these difficulties. For example, object-oriented programming has been identified as a threshold concept in computing through interviews with students, this enabled instructors to blend this concept within a context which may be more easily understood [9]. A threshold concept is rarely acquired straightaway but requires an amount of time for the student to make the transition. This transition period is referred to as the liminal space and it is in this point that a student is likely to encounter difficulties, including a significant emotional reaction to this transition [76]. A consequence that is important to consider is that surface level learning may occur as a result of lecturers incorrectly assuming that students have overcome a threshold concept [9]. Chin [16] defines a student's approach as surface learning when they "tend to memorise discrete facts, reproduce terms and procedures through rote learning" and the student fails to link the specific exercise in relation to their wider learning. Correlating new learning with previous knowledge may be an important aspect of learning AI and overcoming threshold concepts, particularly in respect to prior learning in mathematics. Implementing custom learning designs to support students through the threshold concepts may include a heavier focus on improving students' metacognition and self-efficacy to give them the tools and confidence to push through the threshold concept and support their transition to assimilated knowledge.

\subsection{Metacognition, Self-Efficacy and Self-Regulation}

"Metacognition refers to the ability to reflect upon, understand, and control one's learning" [81]. This is an important technique which enables learners to self-monitor and self-regulate to advance a skill set [80]. The aim of metacognition is to aid individuals in their awareness, allowing them to plan and monitor their learning, which can directly improve their performance [81]. Metacognition also encompasses the relationship "between a student's confidence and their performance [55]. Self-efficacy and confidence measures are related as students are inherently required to express a level of confidence when solving a specific problem posed to them, moreover students' self-judgements of their own confidence level implores the student to monitor their metacognition [86]. Confidence as a construct 'represents an accumulated experience that is used profitably in the process of decision-making' [86]. Therefore, issues relating to confidence level can adversely affect student decision making, hindering learning progress as students may wrongly assess their confidence level.

Understanding any deficits students have in their self-regulating techniques may help to inform pedagogical methods to aid students in overcoming threshold concepts. For example, helping students to reflect on their learning may highlight specific areas which require further attention. Self-regulation entails the "monitoring and managing of one's cognitive processes" as well as control over factors such as emotions, behaviour and environment pertaining to learning [63]. We believe that the processes and understanding which occur through self-regulation may aid students in their navigation of the liminal space when acquiring a threshold concept. This is out of scope for this study; however, it is to be explored at a later date. 
2.3.1 Strategies to Improve Metacognition, Self-Efficacy and Self-Regulation. The proliferation of technology within learning has enabled various new learning techniques to be trialed. The use of this technology can improve student self-monitoring through the use of quizzing with immediate feedback and gamification. These techniques have also been linked with motivation through new insights into the human reward system, findings demonstrate that motivation provided by games of chance generate additional dopamine [49].

There are a number of strategies based around the concept of improving student's metacognition and ability to self-regulate their learning, one of these is the use of problem-posing education, recommended by Freire [30] as opposed to banking education, where education becomes an act of depositing information [31]. Problem-posing education bolsters students critical thinking and "stimulates true reflection and action upon reality" [30]. Teaching metacognitive strategies within the context of the specific course discipline has shown impressive results in that students who participated in this particular study achieved significantly higher grades than non-participants [95]. The metacognitive strategies used included social interactions which promote the transfer of high-level thinking skills based upon advice and guidance from the instructor [95].

We sought to identify the current learning strategies students apply, through the use of questionnaires and observation. We feel that improving learning skills alongside instruction relating to the field may help students through the liminal space and conquer the threshold concepts within this domain. To determine the best practices within AI education, we also felt it was necessary to investigate current practices within computing and data science.

\subsection{Programming and Data Science Education}

Teachers in computing have previously sought to identify some of the issues faced by students when learning computing concepts and techniques. Dale [24] posted an online questionnaire for lecturers asking what they determined the most difficult topic to teach in an introductory computer science course. The research identified four main areas including problem solving, programming, object-oriented design and lack of student maturity. The difficult nature of learning to program has also been acknowledged alongside the high dropout rates for such courses [75][71], and is pertinent to AI education as programming skills are required. Awareness of the importance of student engagement and student variation requires teachers to be adaptable to meet students' needs, it is also important to recognise that specific topics will require longer and greater emphasis than others [76]. This study aims to identify which topics within this domain will require greater emphasis.

2.4.1 Programming. Most undergraduate computer science courses include modules that specify a teaching of theory, the propositional knowledge and practical application of that theory to ensure procedural knowledge [90]. Questioning and exploration of concepts through computational modelling and programming enables students to increase their engagement with the theoretical concepts being taught [23]. This is a common pedagogical approach based on constructivist ideas and active learning [39]. As AI modules are within the computer science domain, we expect AI courses will follow this practice. However, lack of prior mathematics knowledge needed to comprehend the theoretical aspects of AI may be exacerbated by the use of programming exercises as students may struggle to identify suitable models for a specific task or may not understand the architecture of a model and how to program this. Therefore, it is important for the module leader to identify the level of cohort mathematics skills at the outset of a course. Programming modules have a number of similarities with AI, including the wide range of abilities and educational backgrounds of the cohort which can lead to a diverse spectrum of successful and unsuccessful outcomes [75]. In our study, the case studies from the participating universities enabled identification of cohort diversity relating to prior knowledge and Manuscript submitted to ACM 
confidence and the impact this may have on module outcomes. This is discussed in greater detail in the Results and Analysis section.

There are a number of possible obstacles which can hinder students progressing from novice to expert within programming including confidence, lack of strategies and mental models [75]. These obstacles can manifest when students have a lack of social persuasion, such as feedback from influential peers [56] which can boost their selfefficacy [71], as well as a scarcity of "soft skills" such as goal setting and critical thinking [34]. The potential obstacles encountered by novice programmers are relevant to all aspects of AI courses due to preconditioned ideas students may have about the domain and computing and mathematics knowledge from previous courses. For example, logically verifiable algorithms have been key to the theory of computing practice, however this differs with machine learning as a typical model is likely abstruse and the verification process "is not a logical proof of correctness" [84].

One key strategy which has been employed to aid students within their progression to expert includes the use of mental models [71]. A mental model invokes a user's internal representation of components and rules of a system. There may be variation regarding the completeness of the model as a synonym for the student's comprehension of the modelled domain [13]. A student's mental model can be enhanced through experiential learning tasks [71]. Research has shown that a student's mental model influences their level of self-efficacy and this in turn can affect course performance [71]. Examining student's preconceptions of machine learning should allow for a clearer understanding of their mental model and any misconceptions. We investigated this as part of our research questionnaire, further detailed in the Methodology section.

2.4.2 Data Science. Data science is a similar topic to AI in terms of content, which relates to data processing [11], although there is an element of ambiguity related to this term and the technical skills that are required. For example, companies looking to hire a data scientist will often expect the candidate to be competent in AI [1]. Many data science courses contain principles related to machine learning [36] and may even cover this topic as part of the course content. From a technical perspective, data scientists "are seen as experts in advanced computational tools, data mining algorithms, statistical analysis, and machine learning" [1]. Research related to the teaching of data science has shown that some courses within this subject do not require students to undertake a course pertaining to probability theory, multivariate calculus, linear algebra or statistics [1], topics which are characteristically associated with introductory AI courses. This may lead to students having difficulty comprehending the heavy mathematical theory involved in such courses.

Recommended practices for teaching a data science course include organising the course around a range of case studies, writing code live during a lecture and minimisation of the use of mathematical notation and instead, where possible, using computational approaches such as visualisation [41]. Within the case study, the use of these best practices will be noted to determine if they are employed when teaching AI.

2.4.3 Programming and Data Science Education Key Points. As AI is often categorized as a form of computing science, there are a number of inherent similarities within the educational approach, such as a mixture of theoretical and practical instruction. Potential barriers to high attainment within such courses include the identified difficulty of learning to program, confidence issues and contention relating to mental models and the influence on self-efficacy. Identified best practice relating to the teaching of data science include case studies and practical examples. Determining which of these practices are employed within AI education will help towards the framework for teaching this domain. 


\section{METHODOLOGY}

As part of this study, we used five different methods for data collection to determine what might constitute best practice in $\mathrm{AI}$ education. As part of the best practice framework, we wanted to determine if mathematics anxiety was an issue and potential methods to alleviate this through self-regulation, as well as identify potential threshold concepts within this domain. One of the main limitations of our study was that participation was voluntary which bounded our response from particular data collection methods. Baruch [5] conducted a review into reasonable response rate in academic studies and found that the average response rate for questionnaires was $55 \%$, however they found that in some cases the response rate was as low as $10 \%$.

One of the research methods for this study was online inquiry relating to institutions offering some form of AI course to determine what type of courses were available and what form these courses take. We looked at UK, EU and US institutions who offered courses at HE level as a starting point, with the specific search criteria of entry requirements, module prerequisites and description of module topics. These search criteria were chosen as we were looking to determine prerequisite mathematics knowledge required for such courses as well as specific AI content covered. The systematic search investigated UK universities first, we then covered European and US institutions in a wider search.

\subsection{Case Studies}

We used case studies at three different universities as a method for this research. We anonymized these as agreed in the research participation form. One of the universities, university A, is part of the Russell Group which are an "association of research-intensive universities" [32]. The other two universities, university B and C are within the top one hundred UK universities guide by The Guardian [91]. The overall aim of the case studies was to comprehend how the subject was taught at that institution and to determine both student and lecturer opinion. The main methods of data collection included semi-structured interviews and questionnaires for the lecturers and questionnaires and the one-minute paper for the students [87]. Observation of lectures was also conducted to collect contextual evidence relating to the student and teacher experience. The aim was to conduct all of the data collection methods at all three universities; however, this was limited by the voluntary nature of the study and the level of data collection permitted at each institution. At university A, the data collected included an interview with the module lead, pre- and post-module questionnaires, observation and the one-minute paper. Data collection differed at the other two universities, the one-minute paper was not completed at either and university $\mathrm{C}$ did not use the questionnaires, however semi-structured interviews and observation were completed at both.

\subsection{Data Collection Method 1: Online Systematic Review of Modules}

To determine the range of AI programmes offered within HE institutions, online information detailing the individual modules covering the topics of AI, machine learning and deep learning was analysed. For clarity, when discussing AI programmes this denotes the overall degree, for example MSc Artificial Intelligence. When detailing specific modules this describes individual courses which comprise the overall degree programme. The search criteria included module pre-requisites, learning outcomes, content, and structure.

The aim of this analysis was to identify core concepts deemed important in an introductory/advanced course and was determined by the reoccurrence of specific themes across all courses. Institutions across the UK, US and Europe were reviewed and specific information recorded included at which level the course was offered (Undergraduate/Postgraduate), whether the course was compulsory or optional, and prerequisites, course content, structure, and the assessment 
procedure. One of the limitations of this method was the narrow scope of the search, the interdisciplinarity of AI means that $\mathrm{AI}$ is often taught on non-computing courses, such as Business degrees. However, computing departments and the AI courses they offer were the main focus of this work.

The data enabled comprehension of course leaders' determination of the importance of particular topics within AI due to their presence on the unit specification. Relevance of additional resources was also noted to assess the popularity of differing modes of information delivery such as preference for online information over textbooks. Due to the limitations of the study, the institutions partaking in this research have been anonymized.

\subsection{Data Collection Method 2: Semi-Structured Interview}

We identified module leaders for interview during the online research review. In total, twenty-three lecturers were contacted with five respondents, a response rate of $21 \%$. The five interviews were conducted with AI lecturers from differing institutions, three of these universities are part of the Russell Group and the further two are former polytechnics, considered part of the "post-1992" universities, which transformed UK HE through widening participation [82]. As a consequence of the response to the call for participants, all interviewees worked in UK universities.

The interviews were undertaken in a semi-structured, open-ended style to gain the interviewees' perspective through how and what questions [10]. Questions (in appendix) referred to the student cohort, module delivery methods, course prerequisites, module content and topics which they felt students struggled with. All of the interviews were either conducted in person face-to-face or via video call. This situational organisation allowed for the observation of body language and the creation of a safe environment where participants could speak freely [97].

The interviews were also used to identify the lecturers' perception of key threshold concepts and troublesome knowledge within the subject domain. This identification is usually the task of the subject instructor and is based on their experience of teaching in the particular domain of interest [83][25]. Threshold concepts can also be identified through course participant enquiry, for example, through discipline specific interviews [83].

\subsection{Data Collection Method 3: Questionnaires}

There were three questionnaires created for this study, one for lecturers who teach some form of AI course and two for students participating in an AI course. It was important to survey both lecturers and students to gain their perspectives as "students' perceptions may be doubted in relation to academics' perceptions" [18]. The questionnaire for lecturers was designed to determine the type of courses they teach relating to AI. Questions covered the course requirements, prerequisite mathematics and programming skills, course content and resources used for additional learning. The lecturers were also asked, based upon their experience, which topics students tend to have difficulty with (questionnaire in appendix). The questionnaires were sent alongside an interview request detailed in section 3.3; however, the response rate was poor at $13 \%$.

Questionnaires designed for students included a preliminary questionnaire for one of the institutions in the case study, university A, over two separate cohort years, to determine the students' background, their level of mathematics and programming competency and their overall expectation of achievement level. Getting students to self-report on their mathematics knowledge and confidence within this domain is one of the key methods in identifying mathematics anxiety [72]. The second cohort also received a course completion questionnaire to determine their experience in learning this topic during the twelve-week MSc course.

Twenty-one students completed the preliminary questionnaire within the first cohort. Within the second cohort, thirty-five completed the preliminary questionnaire but only seven completed the post-module questionnaire. The 
response rate for the post-module questionnaire was lower however, there are a number of possible reasons for this including optional participation. The preliminary questionnaires were completed on paper within class whereas the post-module questionnaire was online and was brought to the students' attention around the time of their exam.

The questionnaire, designed for completion at the end of the module was identical for all participating universities (university A and B) apart from the listed course content. The specific topics from the course were catalogued to assist the students in determining which they found the most challenging and those they were still unsure about. We wanted to determine how confident the students felt about applying AI after course completion to provide insight into their experience on the course. Students were also asked which additional resources they used and how useful they found these. Demographics such as age and gender were also recorded to determine who is undertaking courses in this domain as well as students' educational background, mathematics and programming experience. There were sixteen respondents from university B. Links to the questionnaires are contained in the appendix.

\subsection{Data Collection Method 4: One-Minute Paper}

Within the machine learning module at university A, the "one-minute paper" method was employed twice within the same cohort to gauge how the students were finding the module, (including their perceived difficulty of certain topics), to aid with the identification of threshold concepts. The one-minute paper is a simple, low-technology technique for gathering regular feedback from students relating to their learning experiences, by anonymously asking students simple questions based on their learning experience [17]. The one-minute paper gives students an opportunity to ask questions which they may have been reluctant to ask within the lecture. Participation in this form of data collection was higher compared to the questionnaires as students were notified that their responses would determine the content of the revision session and that questions from the paper would be addressed. Over the two-week period that this data collection took place, thirty-one students participated out of a class of around fifty. As with all methods of data collection the one minute paper was optional.

One of the potential benefits of the one-minute paper is its capacity to promote student reflection [87]. Due to the block taught nature of the participating university, which entails shortened, time intensive modules, delivered one at a time [27], the same student cohort completed the one-minute paper at the end of each week of lectures which were held over a two-week period. The module was a masters level course and covered content on both machine learning and deep learning, culminating in a practical project applying a range of the concepts taught.

As part of the paper students were asked to mark the topics covered in that week's lectures which they perceived as the most difficult and to list any subjects which they were still unclear on. To conclude the exercise, students were asked to rate their confidence in their comprehension of the topics on a scale of one to ten. The confidence scale was included to comprehend how well the students thought they were understanding and learning the material. The one-minute paper used can be found in the appendix.

\subsection{Data Collection Method 5: Observation}

Observation, as a research method, has a number of advantages including the "potential to yield more valid or authentic data than would otherwise be the case with mediated or inferential methods" [19]. Observation can also provide data on "interactions, processes and behaviours that goes beyond the understanding conveyed in verbal accounts" [74].

Observations were completed at the three universities in the case studies, two of the modules observed were undergraduate courses (university B and C) and one at master's level (university A). Two of the courses were specifically focused on machine learning (university A and C) and one was an introduction to AI (university B). Overall, thirty Manuscript submitted to ACM 
sessions were observed, fourteen on the block taught postgraduate module at university A, twelve at university B, which was a semester long module and four at university $\mathrm{C}$ which had an alternate structure of lecture then practical session. An observation guide was created to structure the sessions to note topics, teaching strategies, the lesson content and interactions between lecturer and student. Any questions students asked pertaining to the material were noted to gain insight into any difficulties students were encountering.

\section{RESULTS AND ANALYSIS}

Analysis of the findings from the five data collection methods enabled insights to be drawn regarding the current educational offerings pertaining to AI. As the study used mixed research methods, mixed methods data analysis was used to analyse the findings. The data obtained through the systematic search of online information was analysed through recurrence of specific themes from the search criteria using descriptive statistics techniques such as frequency distribution [64]. Both interview and observation data were transcribed, segmented, and coded into categories. Standardisation was also used for the interview data to ensure it was comparable. Response frequency and thematic occurrence was used to identify common AI topics which were perceived as troublesome on both the questionnaires and one-minute papers. Further details on analysis methods will be discussed below.

\subsection{Online Information Findings}

As part of this study, we conducted online analysis focusing on the UK, as well as the US and European universities, which were present on top university lists such as the Complete University Guide [20]. Nine were reviewed in depth, five of the universities are part of the Russell Group which is a "self-selecting body representing Britain's foremost research-led universities" [92], another three of the universities are in the Complete University Guide top fifty UK university league table for 2022 [20] and one of the universities is a well renowned US institution.

From this analysis, modules specific to this domain are offered at both undergraduate and postgraduate levels as both compulsory and optional modules within a host of degree programmes. Table 1 outlines, to the best of our knowledge, the current degrees offered by each institution which offer some form of AI module. Some universities, for example Russell Group \#2 and \#3 offer interdisciplinary courses such as Computer Science and Philosophy. Students enrolled on this degree may have differing educational backgrounds which would need to be taken into account when teaching the more technical material. Table 1 also demonstrates the range and variability of AI modules offered by the universities, with many also offering specialisations within this field, such as computer vision and robotics.

The majority of these modules require a high level of mathematics knowledge, particularly in probability theory, calculus and linear algebra. All of which are pertinent to cognition of the theory of AI. In some cases, the institution required a formal mathematics qualification, however, the majority offer refresher sessions on these topics within the module content. Based upon this initial analysis, some universities do not require knowledge of statistics for admission onto their AI modules. This omission may lead to some students struggling to grasp some of the theoretical aspects of AI, due to its mathematical foundation which could have implications on student confidence and mathematics anxiety.

Module content depended upon the overarching topic of the module for example, artificial intelligence, machine learning or deep learning and whether this course was introductory or advanced, taught at undergraduate or postgraduate level. The majority of courses covered some form of supervised and unsupervised learning and specific models such as convolutional neural networks and recurrent neural networks. Some universities only list a broad course overview stating that for instance unsupervised learning will be covered, however some institutions specify individual models such as recurrent neural networks. 
Table 1. Prerequisites related to Al modules offered by the researched institutions

\begin{tabular}{|c|c|c|c|}
\hline University & Degree Programme & Modules Offered & Module Prerequisites \\
\hline $\begin{array}{l}\text { Russell Group } \\
\text { University \#1 }\end{array}$ & $\begin{array}{l}\text { BSc/MEng: Computer Science, } \\
\text { Mathematical Computation, } \\
\text { Computational Finance. } \\
\text { MSc: Computational Statistics } \\
\text { and Machine Learning, Computer } \\
\text { Graphics, Vision \& Imaging, Data } \\
\text { Science and Machine Learning, } \\
\text { Machine Learning, Robotics and } \\
\text { Computation. }\end{array}$ & $\begin{array}{l}\text { Supervised Learning, Advanced } \\
\text { Deep Learning and Reinforcement } \\
\text { Learning, Advanced Topics in Machine } \\
\text { Learning, Applied Machine Learning, } \\
\text { Graphical Models, Introduction to } \\
\text { Deep Learning. } \\
\text { Level: UG and PG }\end{array}$ & $\begin{array}{l}\text { Basic mathematics, calculus, probability } \\
\text { theory, linear algebra, Python } \\
\text { coding skills. }\end{array}$ \\
\hline $\begin{array}{l}\text { Russell Group } \\
\text { University \#2 }\end{array}$ & $\begin{array}{l}\text { All courses BA/Masters: } \\
\text { Computer Science, Mathematics } \\
\text { and Computer Science, Computer } \\
\text { Science and Philosophy. }\end{array}$ & $\begin{array}{l}\text { Machine Learning, Advanced Machine } \\
\text { Learning. } \\
\text { Level: UG and PG }\end{array}$ & $\begin{array}{l}\text { Linear algebra, calculus, } \\
\text { probability theory, continuous } \\
\text { mathematics, design and analysis } \\
\text { of algorithms, programming skills. }\end{array}$ \\
\hline $\begin{array}{l}\text { Russell Group } \\
\text { University \#3 }\end{array}$ & $\begin{array}{l}\text { BSc/MEng: Computer Science, } \\
\text { Computer Science and Electronics, } \\
\text { Computer Science and Mathematics. } \\
\text { MSc: Digital Health, Data Science, } \\
\text { Financial Technology with Data } \\
\text { Science. }\end{array}$ & $\begin{array}{l}\text { Machine Learning, Artificial Intelligence } \\
\text { with Logic Programming, Applied Deep } \\
\text { Learning. } \\
\text { Level: UG and PG }\end{array}$ & $\begin{array}{l}\text { Linear algebra, multivariate } \\
\text { calculus. }\end{array}$ \\
\hline $\begin{array}{l}\text { Russell Group } \\
\text { University \#4 }\end{array}$ & $\begin{array}{l}\text { BEng/MEng: Computing Specialisms: } \\
\text { AI and Machine Learning, Visual } \\
\text { Computing and Robotics, } \\
\text { Management and Finance. MSc: } \\
\text { Advanced Computing, AI. }\end{array}$ & $\begin{array}{l}\text { Introduction to Model Based AI, } \\
\text { Introduction to Machine Learning, } \\
\text { Computer Vision, Mathematics for } \\
\text { Machine Learning. } \\
\text { Level: UG and PG }\end{array}$ & $\begin{array}{l}\text { Logic and Prolog, essential skills } \\
\text { programming and mathematics, } \\
\text { linear algebra, statistics. }\end{array}$ \\
\hline $\begin{array}{l}\text { Russell Group } \\
\text { University \#5 }\end{array}$ & $\begin{array}{l}\text { BSc: Computer Science. } \\
\text { MSc: Data Science, Cloud Computing. }\end{array}$ & $\begin{array}{l}\text { Machine Learning } \\
\text { Level: PG }\end{array}$ & None listed. \\
\hline US University & Computer Science (UG and MS) & $\begin{array}{l}\text { Machine Learning. } \\
\text { Level: Not listed }\end{array}$ & $\begin{array}{l}\text { Knowledge of basic CS principles, } \\
\text { coding skills, probability theory, } \\
\text { linear algebra. }\end{array}$ \\
\hline $\begin{array}{l}\text { Top } 50 \text { UK } \\
\text { University \#1 }\end{array}$ & $\begin{array}{l}\text { Computing MA, Computing Science } \\
\text { BSc/MEng. MSc: Artificial Intelligence, } \\
\text { Data Science. }\end{array}$ & $\begin{array}{l}\text { Grand Challenges of Computing and } \\
\text { Artificial Intelligence. Level: UG }\end{array}$ & None listed. \\
\hline $\begin{array}{l}\text { Top } 50 \text { UK } \\
\text { University \#2 }\end{array}$ & $\begin{array}{l}\text { BSc: Artificial Intelligence, Computer } \\
\text { Science, Data Science. } \\
\text { MSc: Advanced Computer Science. }\end{array}$ & $\begin{array}{l}\text { Introduction to Intelligent Systems, } \\
\text { Cognitive Neural Networks. } \\
\text { Level: UG }\end{array}$ & $\begin{array}{l}\text { Further Object-Oriented Programming } \\
\text { module, A-Level Mathematics or } \\
\text { equivalent. }\end{array}$ \\
\hline $\begin{array}{l}\text { Top } 50 \text { UK } \\
\text { University \#3 }\end{array}$ & $\begin{array}{l}\text { BSc: Computer Science Specialisms: } \\
\text { Artificial Intelligence. MSc: Computer } \\
\text { Science, Advanced Computer Science, } \\
\text { Data Science. }\end{array}$ & $\begin{array}{l}\text { Intelligent Systems, Machine Learning } \\
\text { and Computer Vision, Artificial } \\
\text { Intelligence and Robotics. } \\
\text { Level: UG and PG }\end{array}$ & None listed. \\
\hline
\end{tabular}

As displayed in Table 2 there is a wide range of variability in content for modules which are offered at similar education levels. The majority of AI modules are either taught in the final undergraduate year or within a postgraduate degree. The modules detailed in Table 2 are the same modules as listed in Table 1. The type of module also determines the complexity of the AI taught, for example more applied modules and introductory courses will not require as much theoretical knowledge as more advanced courses. Russell Group University \#4 offers a specific introductory course in machine learning which gives a broad overview of the field and acts as a basis on which students can continue onto more advanced studies. Universities such as Russell Group University \#1 and \#2 take a more in-depth theoretical approach, particularly at Russell Group University \#1 where the focus is on optimisation and the challenges of the various machine learning approaches. This variability between institutions, particularly within modules offered at a similar cohort level (e.g., undergraduate and postgraduate) displays the lack of a discipline specific benchmark necessary to form a coherent educational approach. This is pertinent as AI, machine learning and probabilistic programming are now considered major technologies for inclusion, particularly within UK master's degree programmes [69]. 
Table 2. Content specific to modules which focus on machine learning

\begin{tabular}{|l|l|l|}
\hline University & Modules Offered & Overview of Content \\
\hline Russell Group University \#1 & $\begin{array}{l}\text { Applied Machine Learning, Advanced Topics } \\
\text { in Machine Learning. }\end{array}$ & $\begin{array}{l}\text { Kernel methods, ICA (Independent Component Analysis), SVM } \\
\text { (Support Vector Machine), regularisation, optimisation, classification, } \\
\text { regression, clustering. }\end{array}$ \\
\hline Russell Group University \#2 & Machine Learning, Advanced Machine Learning. & $\begin{array}{l}\text { Supervised learning, unsupervised learning, Bayesian neural networks, } \\
\text { autoencoders, RNN (Recurrent Neural Network), backpropagation, } \\
\text { LSTM (Long Short-Term Memory), CNN (Convolutional Neural Network), } \\
\text { clustering. }\end{array}$ \\
\hline Russell Group University \#4 & Introduction to Machine Learning. & $\begin{array}{l}\text { Decision trees, k-nearest neighbour, regression, neural networks } \\
\text { (perceptron, backpropagation). }\end{array}$ \\
\hline Russell Group University \#4 & Machine Learning. & $\begin{array}{l}\text { Supervised learning (regression, decision trees, SVM, k-nearest neighbour), } \\
\text { unsupervised learning, deep learning (CNN, RNN, LSTM, autoencoders) } \\
\text { PCA (Principle Component Analysis). }\end{array}$ \\
\hline $\begin{array}{l}\text { US University } \\
\text { Top 50 UK University }\end{array}$ & Machine Learning. & $\begin{array}{l}\text { Supervised learning (logisitic regression, perceptron, naive Bayes, SVM), } \\
\text { unsupervised learning (clustering, k-means, PCA, ICA), deep learning } \\
\text { (neural networks, backpropagation). }\end{array}$ \\
\hline
\end{tabular}

Assessment methods for these courses predominantly involve an exam and coursework. This form of assessment allows instructors to examine both the students theoretical understanding as well as their practical application. Within these modules, the assessment methods often reflect the overall aim of the module, for example, the Applied Machine Learning module, detailed in Table 2 as offered by the Russell Group University \#1 employed a formative assessment method of three challenges each weighted at $10 \%$ for the overall mark. This choice of coursework in conjunction with summative assessment taking the form of an exam, reflects the modules aim in teaching students how to implement machine learning in practice. The use of both exam and coursework provides an opportunity for students who may have low confidence in their technical skills, predominantly assessed through coursework, or mathematics anxiety related to the theoretical elements of this subject, assessed through the exam, a chance to demonstrate their strengths within these areas. Therefore, the use of mixed assessment methods may be best practice within AI. Most modules consisted of both lectures and practical sessions alongside a reading list to provide further guidance and instruction. These instructional techniques are routine within other computing pedagogies, this will be reviewed in the case studies to determine its prevalence and use within AI modules.

\subsection{Interview Results}

The data collected from the semi structured interviews was first transcribed, then segmented into specific descriptive units, which were "prerequisites", "pedagogy", "content" and "perceived difficulties". These segments were then coded into more specific categories such as "supervised learning" for the "content" category, then similarities and distinctions were determined through frequency analysis. Based upon the interviews undertaken, four of the five instructors taught courses delivered on an undergraduate program. All modules were taught through a mixture of lectures and practical sessions to enable students to comprehend the theory and then undertake practical examples. One of the interviewees advised that they "think students learn better by doing something" and that they "try to make it easy to see an end result" for the practical tasks they set for students, this is an example of implementation of active learning pedagogy [22].

Module content varied depending upon the overarching theme, however all of the courses contained some form of supervised and unsupervised learning and instruction on neural networks, implying that these are essential topics for inclusion on an AI course. $66 \%$ of the lecturers stated that students had issues with the theoretical aspects of the course 
compared to the practical work. The interviewees were questioned on any additional resources they used as part of their teaching. All respondents stated that they used online resources to supplement material covered within the lectures and to provide further detail on topics covered. The prevalence of online resources as a learning tool suggests that this method of instruction provides a useful service to bolster lecture material, the popularity of this method amongst lecturers may reflect a preference by students for this type of material.

\subsection{Questionnaire Results}

The questionnaires completed by AI lecturers and students participating in the case studies have been analysed through descriptive statistics and statistical techniques including analysis of variance to determine any differences among the groups.

4.3.1 Lecturer Questionnaire. The low response rate to the questionnaire for lecturers teaching AI means that the results were limited, however they did provide a good indication of the expectations the lecturers have of students, the type of content they teach and any specific teaching strategies they employ. The majority of the lecturers expected students to have knowledge of linear algebra, probability theory and familiarity with basic statistics before starting their module. Results from the frequency analysis indicated that the most commonly taught topics included linear regression, support vector machines, convolutional neural networks, principal component analysis and Bayesian machine learning. Respondents also noted that the most common student difficulty was with the mathematical aspects of the module and identified the importance of real-life examples and practical projects to aid students with their learning.

4.3.2 Pre-Module Student Questionnaire. The pre-module questionnaire was completed within university A. Participating in the case study were two differing cohorts of students completing the same module. This postgraduate module in Machine Learning was block taught and covered both machine learning and deep learning. The majority of students on the course had a mathematics attainment level of A-Level or equivalent at 37\%, with mathematics as a major part of their undergraduate degree the second most frequent at $26 \%$. The participants were asked to rate their confidence in their mathematics and programming ability on a scale of one to ten (ten being exceptionally confident), the average confidence level in mathematics was 6.6 and the average confidence in programming was 6.2 . The students were also asked whether they expected to find the theoretical or practical aspect of the module more difficult, $71 \%$ selected theoretical. The mean confidence level for student's expectation to do well in the module was 6.6.

One-way between groups ANOVA, a statistical test to compare the variance between different groups [66], was carried out to determine if there was a difference in self-reported mathematics confidence for the different groups of mathematics attainment. These groups included GCSE, A-Level or equivalent, undergraduate degree and specifically whether this was in Mathematics. There was no significant difference found, however we did find that the higher the level of mathematics attainment, the higher the self-reported confidence level. This highlights the variation in students educational background and the impact this can have on student self-efficacy.

Determining which learning strategies the students were going to use was important to identify which methods they thought would aid them with their learning. The most popular learning strategies chosen by the students included note taking, practical exercises and online guidance. The strategies that the participants expressed they would not use were more holistic strategies such as reflection, goal setting and self-evaluation. As this was a multiple-choice question there was no scope to ask the reasoning behind their choice. However, this has potential for a future study pertaining to perceived efficacy of specific learning strategies.

Manuscript submitted to ACM 
The students were asked to write a brief description of what they thought machine learning was. There were a range of answers which were categorised into groups such as "Prediction", "Modelling" and "Classify data." The most populated groups were "Learning/extracting knowledge from data", "Prediction" and the "Other" category. The "Other" category was composed of answers which did not fit any other group, answers included "it is used quite widely by a lot of companies" and "a combination of mathematics and programming."

4.3.3 Post-Module Questionnaire. There were two post-module questionnaires, one within the Russell Group university A, Machine Learning postgraduate module and the other at the post 1992 university B undergraduate Artificial Intelligence module. Both of the questionnaires were identical apart from content listed for the question asking students which topics they found the most challenging.

The majority of the students from the undergraduate module (university B) had a mathematics attainment level of GSCE or equivalent at $50 \%$, with the second highest being A-Level or equivalent at $31 \%$. The level of mathematics confidence was much more evenly spread than the other university, however none of the participants rated their confidence below a $5.56 \%$ of students found the practical aspects of the module more difficult than the theoretical. The participants identified the most challenging topics as knowledge representation, search algorithms, k-means algorithm, artificial neural networks, multi-layer perceptron and backpropagation. The participants identified their most useful study strategies as note taking and practical exercises, however they also listed more holistic approaches such as goal setting and reflection.

Within the Russell Group university (university A), the participants of the questionnaire were the same students who completed the preliminary questionnaire. The participants identified the most challenging topics as backpropagation, supervised and unsupervised models and deep learning. Supervised and unsupervised models and deep learning are both broad categories which would require further investigation to determine specific issues within these domains. There was an even spread between respondents who thought mathematics was challenging and respondents who didn't find mathematics difficult, this may reflect the variety of mathematics educational background within this cohort. The participants identified note taking and practical exercises as the most useful learning strategies.

4.3.4 One-Minute Paper Results. The one-minute paper was completed by one of the cohorts from university A, the same group of students completed both rounds of the paper. Q1: Which topic(s) did you find the most difficult this week and Q2: Which topic are you still unsure on, required frequency analysis to determine any unifying concepts which the students identified as troublesome. Content analysis was achieved on the specific question's students asked through open coding, categorisation and frequency of occurrence [19].

The postgraduate Machine Learning module was block taught, lasting a duration of three weeks. Participation in the one-minute paper was optional and students were asked to complete it after each week of the taught material. The exercise was not conducted in the third week as this consisted of guest lectures which were not assessed. The most frequent responses to Q1 were the support vector machine and the multilayer perceptron. The main topics which students were still unsure on were the convolutional neural network and the recurrent neural network with $22 \%$ each, making up nearly half of the overall responses.

There were two common themes that emerged from Q3: Any specific questions? There was confusion with the backpropagation algorithm and the students were unsure on feature engineering. $57 \%$ of respondents mentioned these two topics. Students also used this question to request further practical examples within lectures. The average confidence level in what they had learnt that week was 5.1 in the first week and rose to 6.8 in the second week, although there was a variation in the confidence levels with some students rating their confidence very low. As the confidence level 
pertained to the topics covered in each week, this rise may reflect the students finding the second week's content easier or the students may have gained more confidence overall within this domain. However, due to the low sample size, specific causations cannot be determined.

4.3.5 Observation Findings. As a standardised observation guide was used during observation sessions, this ensured that the results were more easily comparable. The data collected during the observation sessions was first transcribed, then content analysis was applied. Content analysis methods included category creation, coding of the content from the transcribed observation guides, logging of frequent occurrences of categories and finally interpretation of results.

Within the three institutions participating in the case studies, observation took place in two undergraduate modules and a master's module. The content on the courses differed due to the educational level and learning outcomes, however common topics between the three modules included decision trees, support vector machines and the k-means algorithm. Two of the courses did refresher mathematics sessions and covered deep learning. Interspersed within the lectures for all of the modules were practical real-life examples, the lecturers of each course also discussed their research within the field which appeared to further engage the students.

The amount of student and lecturer interaction was varied amongst the institutions with interaction being at a minimum within some lectures. At university B, students were given a group task within each lecture which enabled active learning and appeared to increase student engagement as the students expected to be questioned on the content. This teaching method also furthered interaction between the lecturer and students as the learners were more forthcoming with questions on concepts which they did not understand.

The number of students attending each lecture varied per session, university A had the highest average attendance at 95\%, however attendance tailed off during the week of guest lectures. University C was a much smaller class of around fifteen students, however attendance was fairly consistent across all sessions. University B had consistent attendance of around thirty-five students which was an average attendance of $58 \%$.

Specific questions that students asked during the lectures often pertained to the merits of choosing specific models over others, for example one student asked, "what is the advantage of the support vector machine over logistic regression?" Other questions related to mathematical notation and the backpropagation algorithm.

\section{SUMMARY OF PRELIMINARY FINDINGS}

\subsection{Mathematics Anxiety and Educational Background}

Based upon analysis of the online information, interviews and questionnaires with the lecturers, some AI modules require a formal mathematics qualification or in-depth knowledge of mathematics topics pertinent to AI. Some of the modules offer booster sessions, however a lack of uniformity in prerequisites may lead to a disparity in students' understanding of theoretical issues within AI and a lack of preparedness amongst the cohort of students. For example, two of the institutions listed in the top $50 \mathrm{UK}$ universities [20] do not list any prerequisites for undertaking their AI based courses. However, the type of modules they offer, such as Machine Learning, and Computer Vision cover topics which require a mathematical basis to fully understand the content. Offering AI as an interdisciplinary course will also have implications relating to pre-requisites and technical skills. One lecturer who was interviewed stated that they "can tell students come from different backgrounds" and that some students struggle with the terminology and applying their previous knowledge to a new topic.

Within the interviews and questionnaires with the lecturers, a consensus was reached that the mathematical aspects of the module are where students encounter the most difficulty. However, within the questionnaires completed by Manuscript submitted to ACM 
students in the case studies, average self-reported confidence in mathematics was above a five for all participating institutions. This may be due to a reluctance to admit low confidence in mathematics skills at this educational level. There was some disparity in mathematics attainment level for the two universities who completed the questionnaires, within the postgraduate module (university A) the majority of students had an A-Level in mathematics. However, on the undergraduate module (university B) the majority of students had achieved GCSE level mathematics. Within the UK education system, GCSE qualifications are level 1 and 2 depending on grade achieved, A-Levels are level 3, an undergraduate degree is level 6 and master's degree level is level 7 [33].

Although students on the postgraduate module had a high-level of mathematics attainment and the average level of mathematics confidence was $6.6,71 \%$ of the students expected to find the theoretical side of the module more complex than the practical aspects. This correlates with the findings from the lecturer interviews which supported the claim that students have greater difficulty comprehending the theory of AI. However, the majority of students on the undergraduate module found the practical aspects more difficult than the theory. One interesting finding and possible explanation in the disparity between the students on the postgraduate module mathematics confidence level and expectation to find the theory more difficult is that the students lack self-regulation and metacognition skills. The students on the undergraduate module reported their use of more holistic learning strategies such as goal setting and reflection, however the students on the postgraduate module did not use such techniques.

\subsection{Threshold Concepts}

Identification of the threshold concepts within the area of AI and creation of a domain framework will give lecturers understanding of the topics within this domain which are considered core knowledge and may be a source of difficulty for students. There were two strands towards identifying the threshold concepts, these were, 1. topics deemed essential to teach as identified through the online analysis, interviews and questionnaires with the lecturers and 2. topics the students had difficulty with, identified through observation, interviews and student questionnaires.

The most frequently taught topics within the AI modules in the case studies included decision trees, support vector machine, k-means algorithm and specific deep learning models such as convolutional neural networks and recurrent neural networks. The online analysis showed a wide range of topics which are covered within the AI domain, from specific applications of AI such as computer vision, to introductory machine learning modules. However, nearly all of the modules contained content relating to supervised and unsupervised models and some form of deep learning.

The topics students most frequently identified as challenging were mainly related to deep learning, particularly multi-layer perceptrons, convolutional neural networks, recurrent neural networks and the backpropagation algorithm. Lecturers in this domain also highlighted clustering as a pivotal topic which corresponded with the student response that they had difficulty particularly with the k-means algorithm.

\subsection{Pedagogies and Best Practice}

Consistent with other areas of computing education, the use of problem based learning and practical examples are seen by both lecturers and students as an effective learning method for AI. Alongside practical examples, the use of real-life examples were highlighted by lecturers in the questionnaires, interviews and observations. The use of these methods not only contextualises the theoretical knowledge within the applied context but also appeared to increase engagement. The lecturers in all of the observed modules also took time to discuss their research within the AI domain which seemed to further immerse the students in their learning. Within AI modules there seems a greater importance in the use of practical, real-life examples as opposed to traditional computing courses. One of the possible explanations for this is 
the amount of content that can be covered on these types of courses, two of the lecturers interviewed mentioned that students often complain about the amount of content covered. Assimilating the different learning algorithms taught into a practical context, for example deciding which model to use has shown to be an issue for the students as identified by the student questions on the one-minute paper.

The assessment procedure for these types of courses, identified through the online analysis and interviews, detail that a mix of exams and coursework is the most common form of assessment. The pedagogical foundation for this assessment methodology is that exams test the student's theoretical understanding, and the coursework determines the student's practical execution of the topics learnt. For students to more readily associate the theoretical aspects of this domain to their practical application there is a need to include more formative work within these types of courses. For example, through supplementary material which students can work through independently to gauge their understanding of concepts, this may also increase student self-efficacy and consequently enable them to become more self-regulated.

Preliminary results from the data analysis suggests that in the modules covered by our study, lecturers often referred students to additional online resources for further information. This supports earlier research where it was found that students are not using textbooks as often and are turning to the internet instead [7]. The shortfall in consistency relating to course prerequisites, specifically mathematics knowledge and the apparent lack of student confidence and capability relating to the theory of AI suggests that both students and lecturers may benefit from an AI online learning tool to supplement module content.

\section{DISCUSSION}

\subsection{Teaching Strategies}

One of the most important issues pertinent to any educational context is awareness of student engagement levels and the variation of skills and contextual knowledge students possess. It is a valuable skill that lecturers are adaptable within their learning methods to meet the varying student requirements. Aligning with threshold concepts and recognising that some topics will require a longer time to be spent ensuring the students understand these topics is particularly relevant within the field of $\mathrm{AI}$ as there are a number of foundation issues such as feature engineering and backpropagation which are often difficult to understand. These topics are essential to understand in order to build a machine learning model and were identified as topics students had difficulty understanding. One possible method to engage the learners and help overcome threshold concepts is the use of practical, real-life examples. For example, deep learning, especially models centered around artificial neural networks were identified as a potential threshold concept, one possible method to help students build a better mental model of this concept is by comparing the artificial neural network to human learning and neural networks in the brain. Students are often engaged and enthusiastic about learning about themselves and this correlation will help them to build a stronger mental model of deep learning. However, it is essential to indicate that this mapping isn't exact to avoid further confusion. A lack of a clear mental model can cause anxiety and low self-efficacy in the student's belief that they can achieve within their module. Students may not have an effective model and may be "susceptible to the fiction that ML has a "hidden mind" [29], therefore it is of particular importance within AI modules to clearly define key concepts.

There was some disparity between the two universities (A and B) which participated in the questionnaires with regard to which aspect of their module they expected or found the hardest. The students on the postgraduate module who had the higher mathematics attainment expected the theory to be more complex to learn. However, the students 
on the undergraduate module experienced more difficulty with the practical elements, although this module was not as mathematically intensive. As evidenced by the online analysis, there is a wide variety of modules offered within the AI domain, with some offering more applied content and others focusing on the theory of a particular sub-discipline such as deep learning. The lack of uniformity regarding course prerequisites and variety of educational backgrounds may lead to difficulty for students within either the practical or theoretical aspects of the module. Therefore, it may be worthwhile offering refresher sessions or supplementary material for mathematics and programming to eliminate any disparity in knowledge levels as well as increase student self-efficacy in their ability to comprehend the more challenging aspects of the module.

A beneficial technique to scaffold engagement in lectures, recognised as part of the observations is the use of group activities. Group activities have been shown to increase student motivation as well as offering the students a perceived support system which is often not felt when working individually [60][52]. Initiating the lecture by giving an overview of the session structure and alerting the students to the fact that there will be an activity, led to students paying greater attention and engaging more with the content. It also fostered a more dynamic and open relationship not only between peers, but also between peers and the lecturer. As a consequence, there was a marked difference between the number of questions the students asked the lecturer in one institution as opposed to the other institutions observed.

\subsection{Mathematics Anxiety and Self-Efficacy}

The results from the study, in particular the student questionnaire indicated the students felt somewhat confident in their mathematics ability. However, the Russell Group cohort of students (university A) overwhelmingly stated that they thought they would struggle the most with the theoretical aspect of AI which is intrinsically linked with mathematics. The variability in students' educational background, both societal and educational, may impact upon their ability to employ appropriate learning strategies to overcome these difficulties with the theoretical material, for example by linking their previous learning with the new material. If students have low self-efficacy, they may not have the emotional capability to persist when in the liminal state of a threshold concept. Equipping students with metacognitive skills and training them to become more self-regulated learners may help build up student resilience when encountering challenging educational scenarios.

Potential strategies to alleviate mathematics anxiety and to boost student's self-efficacy includes retesting and offering refresher sessions within an AI course to try and balance the inequality of knowledge. Offering retesting within a course can benefit the students in a number of ways as the initial test result works as a form of feedback for the students. A successful experience within a test can counteract the feeling of failure experienced in the past, it can also act as a psychological safety net for students who experience exam anxiety [50] which has also been linked to mathematics anxiety [3]. The results from the online analysis indicated that a significant percentage of AI courses use exams as a form of assessment, offering retesting or low stakes tests throughout the course may ease student anxiety pertaining to this form of assessment, as well as boosting student's self-efficacy by gaining feedback on their progress.

Distance learning has also been shown to benefit student anxiety in relation to mathematics [89]. The concept of distance learning and online learning are often used synonymously, technological advances have updated distance learning methods to provide access to greater educational provision [62]. The findings from both the interviews with AI lecturers and the student questionnaire indicate that online resources are a popular learning tool within this domain. Creation of an online tool incorporating mathematics knowledge specific to AI and incorporation of different metacognition and self-efficacy strategies may help students to ultimately become more self-regulated and to aid their anxiety relating to mathematics and the theory of AI. 


\subsection{Confidence}

Students' confidence and their ability to reflect accurately on their own learning are important skills in academia as it allows greater control over learning. Equipping students with strategies to reflect and self-regulate is often not a priority on academic courses due to time constraints, however, it has been shown that interventions focused on equipping students with learning strategies have improved assessment outcomes [38].

The use of the one-minute paper was to encourage the students to reflect upon their experiences within the course and to enable them to express their concerns regarding specific content. The one-minute paper was employed on a block taught module, this type of format is more intensive than a traditional layout with teaching taking place over a shorter timescale, for example over one semester. The one-minute paper was particularly appropriate for this teaching style due to the intensity and fast pace of instruction. The one-minute paper may be a particularly relevant strategy for AI courses due to the concerns expressed by the students that these modules are too fast paced and cover a lot of material. The one-minute paper can be used to not only engage the students in reflection, but to also alert the lecturer to any topics the students are struggling with.

Another possible method of bolstering student confidence is through the use of sequential tasks which increase in difficulty over a period of time. This would enable the student to gain positive experiences within the AI domain instead of starting at a high complexity level which almost immediately causes the student to doubt their ability. However, a balance needs to be struck with the complexity level to ensure that some higher-achieving students are not deterred from continuing in their studies if they feel the material is "too easy". This is especially pertinent in AI courses due to cohort diversity. One method of improving student confidence based upon the findings from the observations is to create an open and supportive educational environment. This approach enabled students to freely ask questions throughout their learning session, expressing aspects of the material which they did not understand and sharing knowledge with their peers.

\subsection{Threshold Concepts}

Rountree [76] describes the role of threshold concepts as providing a "model for academics in higher education to develop their teaching and support learning." Identification of these concepts within AI will increase lecturers' awareness of the specific aspects of this field that students may encounter difficulties with, and they can then plan and implement learning strategies to aid with the students' understanding. Due to the limitations of the data collection in regard to response rate and narrow selection of institutions and modules, the potential threshold concepts identified in this study will require further research to bolster these findings. However, these findings have contributed towards a framework for teaching AI as topics to be aware of which may cause students difficulty.

The results from this research indicate that deep learning is an area that students are either encountering issues with or is seen as an important topic which requires greater instruction time. For example, three out of the five lecturers who were interviewed taught deep learning within their course and within the one-minute paper, students specifically mentioned the recurrent neural network and multi-layer perceptron as being the most testing to comprehend. Further research is needed to discover exactly what the issue is surrounding these models. However, both of these models are neural networks which may indicate a wider issue with comprehension of this architecture. Students also mentioned difficulty with the backpropagation algorithm within the one-minute paper, which is also intrinsic to neural networks. Based upon the observation sessions, neural networks are currently being taught in the same manner as other concepts 
in AI. The findings from this study indicate that concepts relating to neural networks may be proving difficult and that this topic may need different learning methods.

\subsection{Towards a Framework for Teaching Al}

Working towards a framework for teaching AI requires identification of the threshold concepts, barriers the students may face in their learning, issues lecturers face and establishing the best practices in pedagogy. This paper initiates the process of creation of the framework, however, iteration of the data collection at a wider scale and with inclusion of more diverse institutions will be required to fully deliver the framework.

The initial outline of the framework, as identified in this paper, starts with the prerequisites for undertaking a module in AI. Depending on the type of module and learning outcomes, prerequisites are often listed, however, due to the variability in educational backgrounds it is good practice to offer either revision sessions on mathematics or programming and to provide supplementary material. The refresher sessions may also help to alleviate any anxiety the students have in either their mathematics and technical skills, providing the supplementary material as a distance learning opportunity, with the use of low stakes questioning with optional retesting may also improve the student's self-efficacy and allow them to build confidence in their skills.

The main threshold concepts identified within this study were within the domain of deep learning, particularly convolutional and recurrent neural networks, multilayer perceptrons and backpropagation. It is important for lecturers to align their teaching strategies with some of the difficulties the students may face when learning the threshold concepts. Some of the best practices for teaching AI identified in this study include the use of practical examples and problem-based learning to embed and contextualize the theoretical knowledge. The use of real-life examples is also important to help the students build an appropriate mental model, for example by associating artificial neural networks with the human brain.

Alongside the AI content it is useful to incorporate activities for reflection and self-regulation to assist the students in their learning and to improve their metacognition. Potential activities include the use of group exercises, this will also help foster relationships between the lecturer and students as well as increase engagement within the lectures. The use of the one-minute paper within this study revealed its value and versatility as a method for the lecturer to monitor progress as well as helping the students to reflect on any difficulties they are encountering.

\section{FUTURE WORK}

This analysis of the AI education domain has enabled insight into some of the difficulties both students and lecturers can encounter within this field. As with any research project there are limitations, many of the limitations of this study centre around low response rate and proliferation of similar types of universities both within the case studies and the online systematic review of modules, as only a snapshot of universities were analysed. We may have missed courses which did cover some form of AI as we did not have access to all of the course material and the lecturer may be teaching aspects of this domain without explicitly stating this in the syllabus. However, this study has led to a basis for further research and some ideas for implementing possible solutions to the issues raised by both lecturers and students. Some of these possible solutions will be trialed within a new Deep Learning module currently being developed.

Repetition of the online review of modules with both a wider scope of universities and geographical area will enable further insight into the type of AI courses being offered. Alongside this review, the questionnaire for lecturers will also be sent with the aim to recruit more participants for both the questionnaires and as potential case studies. Iteration of the data collection methods for students within differing cohorts will enable further analysis of the barriers students 
encounter when undertaking education within this area. The further research will enable greater investigation into the best practices and provide more data and insights for the framework, including conformation of the threshold concepts in AI.

\section{CONCLUSION}

The growing interest in AI related courses at HE level, juxtaposed with the shortage of skilled individuals to fill the increasing number of posts within this sector necessitates research into the educational provision within this field. This article has explored many facets of educational difficulties and has proposed a number of strategies to help mitigate these issues. The aim of this paper was to identify potential best practices and to initiate the creation of a framework for teaching AI. Some of the best practices identified through this study include the necessity to outline clear prerequisites, specifically related to the module content and learning outcomes. However, the use of prerequisites will not eliminate the variation in student educational background, therefore offering refresher sessions is important to attempt to align knowledge, particularly in mathematics and programming. Alongside the differences in student educational background, students may also experience a lack of confidence in particular aspects of the module, for example, the Russell Group university which participated in the case study had the highest level of mathematics attainment, however the majority of students expected to struggle with the theory of machine learning. One identified strategy to improve student confidence is through the use of supplementary material, particularly resources which offer students the opportunity to improve their self-efficacy, for example through reflection.

One of the teaching strategies which was highlighted as useful by both the lecturers and students was the use of practical and real-life examples to help the students build a mental model and embed the theory within a usable, practical context. Practical examples are prevalent throughout computing education; however, we feel they have higher importance in building the students mental model within the AI domain. This is due to the inherent differences between $\mathrm{AI}$ and other computing domains, where the majority of students will have experience. For example, in traditional programming the programmer creates the steps detailing how to achieve the outcome, whereas in machine learning the programmer defines the objective "that the system is trying to maximise" [84] and the verification task "is not a proof of logical correctness, but rather a statistical demonstration of effectiveness" [84]. These concepts can be alien and difficult to grasp for students who have experience within other computing domains, which as we have seen from the online review that AI modules are mainly offered as part of computing degree programmes.

In conjunction with the identification of barriers to student learning, determining the threshold concepts within this domain was also an important step towards the framework. Our main criteria for the threshold concepts were topics which were core to comprehending the domain and topics which both students and lecturers identified as difficult. The core topics identified pertained to supervised and unsupervised learning, specifically models such as decision trees, the support vector machine and the k-means algorithm. The majority of courses also covered some form of deep learning, specifically artificial neural networks. There was some overlap between topics deemed essential to teach and topics which students had difficulty learning, including the support vector machine and the k-means algorithm. Identification of these topics is the first step towards creating a clearly defined set of threshold concepts, which will require further iterations of this study with a more diverse set of participants.

This study contributes to a limited pool of research pertaining to AI education. We sought to provide guidance on pedagogical strategies to lecturers within this field and further the understanding of the difficulties faced when undertaking education within this domain with the aim of improving student experience.

Manuscript submitted to ACM 


\section{ACKNOWLEDGMENTS}

We would like to thank all of the institutions who participated in this research.

\section{REFERENCES}

[1] Daniel Asamoah, Derek Doran, and Shu Schiller. 2015. Teaching the Foundations of Data Science: An Interdisciplinary Approach. In Pre-ICIS SIGDSA Workshop. Texas, 1-9. http://arxiv.org/abs/1512.04456

[2] Mark Ashcraft, H, Elizabeth Kirk, P, and Derek Hopko. 1998. On the cognitive consequences of mathematics anxiety. The development of mathematical skills. Studies in developmental psychology. November (1998), 175-196.

[3] Mark H. Ashcraft. 2002. Math anxiety: Personal, educational, and cognitive consequences. Current Directions in Psychological Science 11, 5 (2002), 181-185. https://doi.org/10.1111/1467-8721.00196

[4] Caroline Baillie, John A. Bowden, and Jan H.F. Meyer. 2013. Threshold capabilities: Threshold concepts and knowledge capability linked through variation theory. Higher Education 65, 2 (2013), 227-246. https://doi.org/10.1007/s10734-012-9540-5

[5] Yehuda Baruch. 1999. Response Rate in Academic Studies. Human Relations 52, 4 (1999), 421-438.

[6] Derek Bell. 2018. Maths anxiety summit 2018. June (2018), 1-21.

[7] Elizabeth Boese. 2016. Just-In-Time Learning for the Just Google It Era. Proceedings of the 47th ACM Technical Symposium on Computing Science Education - SIGCSE '16 (2016), 341-345. https://doi.org/10.1145/2839509.2844583

[8] James Bourne. 2019. 93\% of firms committed to AI - but skills shortage posing problems. https://artificialintelligence-news.com/2019/05/21/93-offirms-committed-to-ai-but-skills-shortage-posing-problems/

[9] Jonas Boustedt, S Gävle, Anna Eckerdal, Robert Mccartney, Mark Ratcliffe, Jan Erik Moström, Kate Sanders, and Carol Zander. 2007. Threshold Concepts in Computer Science : Do They Exist And Are They Useful ? SIGCSE '07 Proceedings of the 38th SIGCSE technical symposium on computer science education (2007), 504-508.

[10] Mary Brenner. 2006. Interviewing in Educational Research. In Handbook of Complementary Methods in Education Research, Gregory Camilli, Judith Green, and Patricia Elmore (Eds.). Routledge, Abingdon.

[11] Robert J. Brunner and Edward J. Kim. 2016. Teaching data science. Procedia Computer Science 80 (2016), 1947-1956. https://doi.org/10.1016/j.procs. 2016.05.513

[12] Daniel Cameron and Kelly Maguire. 2017. Public views of Machine Learning: Digtial Natives. (2017). https://royalsociety.org/topics-policy/projects/ machine-learning/

[13] Jose Canas, Maria Bajo, and Pilar Gonzalvo. 1994. Mental models and computer programming. Human Computer Studies 40 (1994), $795-811$. https://doi.org/10.1063/1.3033202 arXiv:0512156v1 [cond-mat]

[14] Rosa Cera, Michela Mancini, and Alessandro Antonietti. 2014. Relationships between Metacognition, Self-efficacy and Self-regulation in Learning. ECPS - Educational, Cultural and Psychological Studies 7 (2014), 115-141. https://doi.org/10.7358/ecps-2013-007-cera

[15] Rodrigo Ceron. 2019. AI, machine learning and deep learning: What's the difference? https://www.ibm.com/blogs/systems/ai-machine-learningand-deep-learning-whats-the-difference/

[16] Christine Chin and David E. Brown. 2000. Learning in science: A comparison of deep and surface approaches. Fournal of Research in Science Teaching 37, 2 (2000), 109-138. https://doi.org/10.1002/(SICI)1098-2736(200002)37:2<109::AID-TEA3>3.0.CO;2-7

[17] John F. Chizmar and Anthony L. Ostrosky. 1998. The One-Minute Paper: Some Empirical Findings. Journal of Economic Education 29, 1 (1998), 3-10. https://doi.org/10.1080/00220489809596436

[18] Martin Coffey and Graham Gibbs. 2001. The Evaluation of the Student Evaluation of Educational Quality Questionnaire (SEEQ) in UK Higher Education. Assessment and Evaluation in Higher Education 26, 1 (2001), 89-93. https://doi.org/10.1080/02602930020022318

[19] Louis Cohen, Lawrence Manion, and Keith Morrison. 2018. Research Methods in Education (8th ed.). Routledge, New York.

[20] Complete University Guide. [n.d.]. Top UK University League Tables and Rankings 2022 Complete University Guide. https://www. thecompleteuniversityguide.co.uk/league-tables/rankings

[21] Glynis Cousin. 2006. An Introduction to Threshold Concepts. Planet 17, 1 (2006), 4-5. https://doi.org/10.11120/plan.2006.00170004

[22] Tom Crick. 2017. Computing Education: An Overview of Research in the Field. Cronfa - Swansea University Open Access Repository April (2017), 1-38. http://cronfa.swan.ac.uk/Record/cronfa43589\%0Ahttps://royalsociety.org/-/media/policy/projects/computing-education/literature-reviewoverview-research-field.pdf

[23] Paul Curzon, Peter McOwan, James Donohue, Seymour Wright, and William Marsh. 2018. Teaching of Concepts. In Computer Science EducationPerspectives on Teaching and Learning in School, Sue Sentence, Erik Barendsen, and Carsten Schulte (Eds.). Bloomsbury Academic, London.

[24] Nell B. Dale. 2006. Most difficult topics in CS1. ACM SIGCSE Bulletin 38, 2 (2006), 49. https://doi.org/10.1145/1138403.1138432

[25] Peter Davies. 2006. Threshold Concepts: How Can We Recognise Them? In Overcoming Barriers to Student Understanding, Ray Land and Jan H.F. Meyer (Eds.). Routledge, Abingdon.

[26] Media Department for Digital and Sport. 2017. UK Digital Strategy. Technical Report. Government of the United Kingdom. https://www.gov.uk/ government/publications/uk-digital-strategy/uk-digital-strategy 
[27] Laura Dixon and Valerie O'Gorman. 2020. 'Block teaching'-exploring lecturers' perceptions of intensive modes of delivery in the context of undergraduate education. Journal of Further and Higher Education 44, 5 (2020), 583-595. https://doi.org/10.1080/0309877X.2018.1564024

[28] Usama Fayyad and Hamit Hamutcu. 2020. Toward Foundations for Data Science and Analytics: A Knowledge Framework for Professional Standards. Harvard Data Science Review 2, 2 (2020). https://doi.org/10.1162/99608f92.1a99e67a

[29] Rebecca Fiebrink. 2019. Machine learning education for artists, musicians, and other creative practitioners. ACM Transactions on Computing Education 19, 4 (2019). https://doi.org/10.1145/3294008

[30] Paulo Freire. 1970. Pedagogy of the Oppressed. Continuum Publishing Company, New York.

[31] Paulo Freire. 2004. The "Banking" Concept of Education. In Educational Foundations: An Anthology of Critical Readings, Alan S. Canestrari and Bruce A. Marlowe (Eds.). Sage, London, 99-111.

[32] Sheila Furey, Paul Springer, and Christine Parsons. 2014. Positioning university as a brand: Distinctions between the brand promise of Russell Group, 1994 Group, University Alliance, and Million+ universities. Journal of Marketing for Higher Education 24, 1 (2014), 99-121. https: //doi.org/10.1080/08841241.2014.919980

[33] GOV.UK. 2020. What qualification levels mean: England, Wales and Northern Ireland. https://www.gov.uk/what-different-qualification-levelsmean/list-of-qualification-levels

[34] Gerald O. Grow. 1991. Teaching learners to be self-directed. Adult Education Quarterly 41, 3 (1991), 125-149. https://doi.org/10.1177/ 0001848191041003001

[35] Wendy Hall and Jérôme Pesenti. 2017. Growing the Artificial Intelligence Industry in the UK. (2017), 77. https://assets.publishing.service.gov. uk/government/uploads/system/uploads/attachment_data/file/652097/Growing_the_artificial_intelligence_industry_in_the_UK.pdf\%0Ahttps: //www.gov.uk/government/publications/growing-the-artificial-intelligence-industry-in-

[36] J. Hardin, R. Hoerl, Nicholas J. Horton, D. Nolan, B. Baumer, O. Hall-Holt, P. Murrell, R. Peng, P. Roback, D. Temple Lang, and M. D. Ward. 2015. Data Science in Statistics Curricula: Preparing Students to "Think with Data". American Statistician 69, 4 (2015), 343-353. https://doi.org/10.1080/ 00031305.2015 .1077729

[37] John Hattie. 2012. Visible Learning For Teachers. Routledge, Abingdon.

[38] J. Hattie, J. Biggs, and N. Purdie. 1996. Effects of Learning Skills Interventions on Student Learning: A Meta-Analysis. Review of Educational Research 66, 2 (1996), 99-136. https://doi.org/10.3102/00346543066002099

[39] Orit Hazzan, Tami Lapidot, and Noa Ragonis. 2011. Guide to Teaching Computer Science: An Activity Based Approach. Springer, New York. 1-285 pages. https://doi.org/10.1007/978-1-4471-6630-6

[40] Ray Hembree. 1990. The Nature, Effects, and Relief of Mathematics Anxiety. Fournal for Research in Mathematics Education 21, 1 (1990), 33-46.

[41] Stephanie C. Hicks and Rafael A. Irizarry. 2017. A Guide to Teaching Data Science. The American Statistician 1305 (2017), 1-34. https://doi.org/10. 1080/00031305.2017.1356747

[42] HM Govermment. 2018. Industrial Strategy Artificial Intelligence Sector Deal. (2018). https://assets.publishing.service.gov.uk/government/uploads/ system/uploads/attachment_data/file/702810/180425_BEIS_AI_Sector_Deal_4_.pdf

[43] Thomas E. Hunt, David Clark-Carter, and David Sheffield. 2011. The development and part validation of a U.K. scale for mathematics anxiety. Journal of Psychoeducational Assessment 29, 5 (2011), 455-466. https://doi.org/10.1177/0734282910392892

[44] Laura Iossi. 2007. Strategies for Reducing Math Anxiety in Post-Secondary Students. Proceedings of the Sixth Annual College of Education Research Conference: Urban and International Education Section (2007), 30-35. http://coeweb.fiu.edu/research_conference/\%5Cnhttp://digitalcommons.fiu.edu/ cgi/viewcontent.cgi? article $=1257 \&$ context $=$ sferc

[45] Ipsos MORI. 2017. Public views of Machine Learning. Findings from public research and engagement conducted on behalf of the Royal Society. April (2017), 87. http://www.ipsos-mori.com/terms.

[46] Marsha Ironsmith, Jennifer Marva, Beverly Harju, and Marion Eppler. 2003. Motivation and Performance in College Students Enrolled in Self-Paced Versus Lecture-Format Remedial Mathematics Courses. Journal of Instructional Psychology 30, 4 (2003), 276-284. https://doi.org/10.1016/j.jaci.2012. 05.050

[47] Sachin Jain and Martin Dowson. 2009. Mathematics anxiety as a function of multidimensional self-regulation and self-efficacy. Contemporary Educational Psychology 34, 3 (2009), 240-249. https://doi.org/10.1016/j.cedpsych.2009.05.004

[48] Peter Jeffcock. 2018. What's the Difference Between AI, Machine Learning, and Deep Learning? https://blogs.oracle.com/bigdata/difference-aimachine-learning-deep-learning

[49] Paul Jones. 2010. Introducing Neuroeducational Research. Routledge, Abingdon.

[50] Sandra M. Juhler, Janice F. Rech, Steven G. From, and Monica M. Brogan. 1998. The effect of optional retesting on college students' achievement in an individualized algebra course. fournal of Experimental Education 66, 2 (1998), 125-137. https://doi.org/10.1080/00220979809601399

[51] Ray Land, Glynis Cousin, Jan H.F. Meyer, and Peter Davies. 2005. Threshold Concepts and troublesome knowledge(3): implications for course design and evaluation. Improving Student Learning and Inclusivity (2005). https://doi.org/10.4324/9780203966273

[52] Shiri Lavy. 2017. Who benefits from group work in higher education? An attachment theory perspective. Higher Education 73, 2 (2017), 175-187. https://doi.org/10.1007/s10734-016-0006-z

[53] Yann LeCun and Martin Ford. 2018. Yann LeCun. In Architects of Intelligence. Packt Publishing, Birmingham.

[54] Jihyun Lee. 2009. Universals and specifics of math self-concept, math self-efficacy, and math anxiety across 41 PISA 2003 participating countries. Learning and Individual Differences 19, 3 (2009), 355-365. https://doi.org/10.1016/j.lindif.2008.10.009 
[55] Priscilla Lee and Soohyun Nam Liao. 2021. Targeting Metacognition by Incorporating Student-Reported Confidence Estimates on Self-Assessment Quizzes. SIGCSE 2021 - Proceedings of the 52nd ACM Technical Symposium on Computer Science Education (2021), 431-437. https://doi.org/10.1145/ 3408877.3432377

[56] C.W. Loo and J.L.F. Choy. 2013. Sources of Self-Efficacy Influencing Academic Performance of Engineering Students. American fournal of Educational Research 1, 3 (2013), 86-92. https://doi.org/10.12691/education-1-3-4

[57] Ursula Lucas and Rosina Mladenovic. 2007. The potential of threshold concepts: an emerging framework for educational research and practice. London Review of Education 5, 3 (2007), 237-248. https://doi.org/10.1080/14748460701661294

[58] Rosemary Luckin. 2018. Machine Learning and Human Intelligence. UCL Institute of Education Press, London.

[59] Andrew Mcafee and Erik Brynjolfsson. 2012. Big Data: The Management Revolution. Harvard Business Review October (2012), 1-9. http: //tarjomefa.com/wp-content/uploads/2017/04/6539-English-TarjomeFa-1.pdf

[60] Alan McLean. 2009. Motivating Every Learner. SAGE Publications, London.

[61] J.H.F. Meyer and R. Land. 2003. Threshold concepts and troublesome knowledge: Linkages to ways of thinking and practising within the disciplines. Improving Student Learning: Improving Student Learning Theory and Practice-Ten Years On. (2003), 412-424. https://doi.org/10.1007/978-3-8348-9837-1

[62] Joi L. Moore, Camille Dickson-Deane, and Krista Galyen. 2010. E-Learning, online learning, and distance learning environments: Are they the same? Internet and Higher Education (2010). https://doi.org/10.1016/j.iheduc.2010.10.001

[63] Linda Nilson. 2013. Creating Self-Regulated Learners: Strategies To Strengthen Students' Self-Awareness and Learning Skills. Stylus Publishing, Virginia.

[64] Lorelli S. Nowell, Jill M. Norris, Deborah E. White, and Nancy J. Moules. 2017. Thematic Analysis: Striving to Meet the Trustworthiness Criteria. International fournal of Qualitative Methods 16, 1 (2017), 1-13. https://doi.org/10.1177/1609406917733847

[65] Harold F. O'Neil and Jamal Abedi. 1996. Reliability and validity of a state metacognitive inventory: Potential for alternative assessment. fournal of Educational Research 89, 4 (1996), 234-245. https://doi.org/10.1080/00220671.1996.9941208

[66] Julie Pallant. 2016. SPSS Survival Manual (6th editio ed.). Open University Press, Berkshire.

[67] Philip David Parker, Herbert W. Marsh, Joseph Ciarrochi, Sarah Marshall, and Adel Salah Abduljabbar. 2014. Juxtaposing math self-efficacy and selfconcept as predictors of long-term achievement outcomes. Educational Psychology 34, 1 (2014), 29-48. https://doi.org/10.1080/01443410.2013.797339

[68] Marc Prensky. 2001. Digital Natives, Digital Immigrants. On the Horizon 9, 5 (2001), 1-6.

[69] QAA. 2019. Subject Benchmark Statement: Computing (Master's). Technical Report October. https://www.qaa.ac.uk/docs/qaa/subject-benchmarkstatements/subject-benchmark-statement-computing-(masters).pdf?sfvrsn=15f2c881_10

[70] R. Quinnell, R. Thompson, and R. J. LeBard. 2013. It's not maths; it's science: Exploring thinking dispositions, learning thresholds and mindfulness in science learning. International fournal of Mathematical Education in Science and Technology 44, 6 (2013), 808-816. https://doi.org/10.1080/0020739X. 2013.800598

[71] Vennila Ramalingam, Deborah LaBelle, and Susan Wiedenbeck. 2004. Self-efficacy and Mental Models in Learning to Program. Proceedings of the 9th Annual SIGCSE Conference on Innovation and Technology in Computer Science Education (2004), 171-175. https://doi.org/10.1145/1007996.1008042

[72] Gerardo Ramirez, Stacy T. Shaw, and Erin A. Maloney. 2018. Math Anxiety: Past Research, Promising Interventions, and a New Interpretation Framework. Educational Psychologist 53, 3 (2018), 145-164. https://doi.org/10.1080/00461520.2018.1447384

[73] Frank C. Richardson and Richard M. Suinn. 1972. The Mathematics Anxiety Rating Scale: Psychometric data. Fournal of Counseling Psychology 19, 6 (1972), 551-554. https://doi.org/10.1037/h0033456

[74] Jane Ritchie, Jane Lewis, Carol McNaughton Nicholls, and Rachel Ormston. 2014. Qualitative Research Methods in Education (2nd ed.). SAGE Publications, London.

[75] Anthony Robins, Janet Rountree, and Nathan Rountree. 2003. Learning and Teaching Programming: A Review and Discussion. Computer Science Education 13, 2 (2003), 137-172. https://doi.org/10.1076/csed.13.2.137.14200

[76] Janet Rountree and Nathan Rountree. 2009. Issues Regarding Threshold Concepts in Computer Science. In Proceedings of the 11th Australasian Computing Education Conference (ACE2009).

[77] Stuart Russell and Peter Norvig. 2013. Artificial Intelligence: A Modern Approach (3rd ed.). Pearson, England.

[78] Jeffrey Saltz, Michael Skirpan, Casey Fiesler, Micha Gorelick, Tom Yeh, Robert Heckman, Neil Dewar, and Nathan Beard. 2019. Integrating ethics within machine learning courses. ACM Transactions on Computing Education 19, 4 (2019). https://doi.org/10.1145/3341164

[79] Amar Sarkar, Ann Dowker, and Roi Cohen Kadosh. 2014. Cognitive enhancement or cognitive cost: Trait-specific outcomes of brain stimulation in the case of mathematics anxiety. fournal of Neuroscience 34, 50 (2014), 16605-16610. https://doi.org/10.1523/JNEUROSCI.3129-14.2014

[80] Lauren Scharff, John Draeger, Dominique Verpoorten, Marie Devlin, Lucie Dvorakova, S, Jason Lodge, M, and Susan Smith. 2017. Exploring Metacogntition as Support for Learning Transfer. Teaching and Learning Enquiry 5, 1 (2017), 1-14.

[81] Gregory Schraw and Rayne Dennison. 1994. Assessing Metacognitive awareness. Contemporary Educational Psychology 19 (1994), $460-475$.

[82] Peter Scott. 2012. It's 20 years since polytechnics became universities - and there's no going back. https://www.theguardian.com/education/2012/ sep/03/polytechnics-became-universities-1992-differentiation

[83] Ruxandra Serbanescu. 2017. Identifying Threshold Concepts in Physics: too many to count! Practice and Evidence of the Scholarship of Teaching and Learning in Higher Education 12, 2 (2017), 378-396. http://community.dur.ac.uk/pestlhe.learning/index.php/pestlhe/article/view/178/207

[84] R. Benjamin Shapiro, Rebecca Fiebrink, and Peter Norvig. 2018. Education: How machine learning impacts the undergraduate computing curriculum. Commun. ACM 61, 11 (2018), 27-29. https://doi.org/10.1145/3277567

[85] Stanford University. 2021. Artificial Intelligence Index Report. Technical Report. https://doi.org/10.1145/3399971.3399984 
[86] Lazar Stankov, Suzanne Morony, and Yim Ping Lee. 2014. Confidence: The best non-cognitive predictor of academic achievement? Educational Psychology 34, 1 (2014), 9-28. https://doi.org/10.1080/01443410.2013.814194

[87] David R. Stead. 2005. A review of the one-minute paper. Active Learning in Higher Education 6, 2 (2005), 118-131. https://doi.org/10.1177/ 1469787405054237

[88] Kay Steven and Liz Thomas. 2019. Attracting Diversity : End of Project Report. Technical Report. https://www.advance-he.ac.uk/knowledgehub/attracting-diversity-end-project-report

[89] Janet A. Taylor and Joan Mohr. 2001. Mathematics for Math Anxious Students Studying at a Distance. Fournal of Developmental Education 25, 1 (2001), 30-37. http://web.a.ebscohost.com/sas/detail?sid=c1259a70-60b0-4cf7-a17e-b9cf790fc1cf\%40sessionmgr4005\&vid=0\&hid=4214\&bdata= JkF1dGhUeXBlPQ\%3D\%3D\#AN=5223062\&db=afh

[90] Matt Tendre and Mikko Apiola. 2013. Three Computing Traditions In School Computing Education. In Improving Computer Science Education, Djordje Kadijevich, Charoula Angeli, and Carsten Schulte (Eds.). Routledge, New York.

[91] The Guardian. 2020. The Best UK Universities 2021 - Rankings. https://www.theguardian.com/education/ng-interactive/2020/sep/05/the-best-ukuniversities-2021-league-table

[92] The Observer. 2003. Ivy League for the UK. https://www.theguardian.com/education/2003/sep/21/highereducation.uk1

[93] The Royal Society. 2017. Machine learning: the power and promise of computers that learn by example. Vol. 66. 125 pages. https://doi.org/10.1126/ scitranslmed.3002564

[94] UK AI Council. 2021. AI Roadmap. Technical Report. https://www.gov.uk/government/publications/ai-roadmap

[95] Simone Volet. 1991. Modelling and coaching of relevant metacognitive strategies for enhancing university students' learning. Learning and Instruction 1, 4 (1991), 319-336

[96] Guy Walker. 2013. A cognitive approach to threshold concepts. Higher Education 65, 2 (2013), 247-263. https://doi.org/10.1007/s10734-012-9541-4

[97] Alice Yeo, Robin Legard, Jill Keegan, Kit Ward, Carol McNaughton Nicholls, and Jane Lewis. 2014. In-Depth Interviews. In Qualitative Research Practice, Jane Ritchie, Jane Lewis, McNaughton Nicholls, and Rachel Ormston (Eds.). SAGE Publications, London.

[98] Erin Young, Judy Wajcman, and Laila Sprejer. 2021. Where are the women ? Mapping the Gender fob Gap in AI. Policy Briefing: Full Report. Technical Report. The Alan Turing Institute. https://www.turing.ac.uk/research/publications/report-where-are-womenmapping-gender-job-gap-ai?_cldee=Yi5hbGxlbjJAbmV3Y2FzdGxlLmFjLnVr\&recipientid=contact-37781e7a802be811811a70106faad2f1b6a1772674d34b249cfb106c2a7b42d5\&esid=e6bc640a-8090-eb11-b1ac-000d

\section{A APPENDICES}

\section{A.1 Link to the student questionnaire}

The link is to the questionnaire the students were asked to complete on completion of their Machine Learning module at university A: https://doi.org/10.25405/data.ncl.16587017.v1.

\section{A.2 Link to the lecturer questionnaire}

The link is to the questionnaire sent to lecturers who teach some form of AI course: https://doi.org/10.25405/data.ncl. 16587020.v1

\section{A.3 One-Minute Paper}

The link below is for the one-minute paper for week one of the Machine Learning module at university A: https: //doi.org/10.25405/data.ncl.16587038.v1

\section{A.4 Interview Questions}

The link below contains the questions for the semi-structured interviews with the lecturers: https://doi.org/10.25405/ data.ncl.16587071.v1 